\title{
ENSINO DE LEITURA NA ESCOLA: UM OLHAR PARA O LIVRO DIDÁTICO
}

\author{
MARISTELA CURY SARIAN ${ }^{1}$ \\ Universidade do Estado de Mato Grosso \\ Av. Tancredo Neves, 1095, Cavalhada, 78200-000, Cáceres-MT, Brasil \\ maristelasarian@unemat.br
}

\begin{abstract}
Resumo. Este trabalho objetiva compreender que sentidos de leitura estão legitimados a circular em uma atividade recortada de um livro didático de língua portuguesa do ensino fundamental. Com vistas a colocar em evidência que espaços para a interpretação são dados aos sujeitos da escolarização neste instrumento de ensino, analisamos esta atividade estabelecendo relação com a Apresentação desse material, assinada pelas autoras. Apresentamos também algumas considerações sobre a entrada do livro didático na escola, a partir do Programa Nacional do Livro Didático (PNLD), dando visibilidade ao funcionamento da autoria, o que nos deu condições para compreender o funcionamento dessa política de ensino na relação com a produção e a transmissão do conhecimento científico no espaço escolar. Sinalizamos, como resultados, uma tensão entre o que se anuncia como novas maneiras de se trabalhar a leitura e o que se propõe enquanto prática de leitura.
\end{abstract}

Palavras-chave: autoria; leitura; ensino; livro didático; análise de discurso; tecnologias.

\begin{abstract}
This study aims to understand which meanings for reading may circulate during an activity extracted from a textbook of Portuguese language for elementary and middle school. To highlight which spaces for interpretation this teaching tool provides for the subjects of schooling, we analyze the activity, connecting it to the Presentation the authors wrote for the material. We also make some considerations about the inception of the textbook at school based on the Textbook National Program (Programa Nacional do Livro Didático-PNLD), giving visibility to the functioning of authorship, which enabled us to understand how this educational policy relates to the production and transmission of scientific knowledge in the school environment. As a result, we point out a tension between what is presented as new ways to work with reading and what is proposed as reading practice.
\end{abstract}

Keywords: authorship; reading; teaching; textbook; discourse analysis; technologies.

\footnotetext{
1 Doutora em Linguística pela Unicamp. Professora da Universidade do Estado de Mato Grosso UNEMAT, onde atua no Programa de Mestrado Profissional em Letras, Unidade Cáceres/MT. http://lattes.cnpq.br/1586873682372220.
} 
Não basta mudar a tecnologia se as perguntas feitas, por meio delas, forem as mesmas do livro didático.

Mariza Vieira da Silva, $2012^{2}$

\section{Introdução}

Este trabalho, inscrito na perspectiva teórica da Análise de Discurso elaborada por Michel Pêcheux e Eni Orlandi, volta-se a questões relativas aos mecanismos que regulam os gestos de interpretação na escola, compreendida como um espaço institucional de disputas por sentidos.

Objetivamos, assim, dar visibilidade ao processo de produção de leitura tomando como corpus uma atividade de língua portuguesa extraída de um livro didático do ensino fundamental em circulação em uma escola no interior do Estado de Mato Grosso. Nomeado "Projeto Telaris: língua portuguesa", do qual recortamos o volume referente ao $9^{\circ}$ ano, o livro é de autoria de Borgatto, Bertin e Marchezi, publicado pela editora Ática em 2012, parte da política empreendida pelo Programa Nacional do Livro Didático $(\mathrm{PNLD})^{3}$.

Nesse movimento, queremos compreender que sentidos de leitura estão legitimados a circular nesse material, que espaços para a interpretação são dados aos sujeitos da escolarização - professores e alunos - ou, em outras palavras, que "condições para a produção da autoria" (CASTELLANOS PFEIFFER, 1995) são autorizadas a comparecer nesse instrumento de ensino.

\section{Entre a produção e a transmissão de saberes na escola, a autoria}

Inicio esta reflexão trazendo a questão da disciplinarização e da didatização dos saberes como condição para se compreender os processos discursivos constitutivos da autoria do livro didático, tomando como referência os trabalhos de Chiss e Puech (1998) e Silva (2005, 2007a e 2007b) e mobilizando as noções de "divisão social do trabalho da leitura" (PÊCHEUX, 2010) e das "coisas-a-saber" de que nos fala também Pêcheux (2008).

Compreendemos o livro didático como um instrumento de ensino constituído e instituído no processo de disciplinarização de um campo do saber que se estabelece, de forma contraditória, entre dois mundos: o mundo da invenção e da produção de saberes,

\footnotetext{
${ }^{2}$ Anotação tomada durante o curso "O processo de escolarização do português como língua nacional: segunda metade do século XX", ministrado pela Profa. Dra. Mariza Vieira da Silva, na UNICAMP, no semestre letivo de 2012/1.

${ }^{3}$ Este trabalho é um recorte dos resultados do projeto de pesquisa "Políticas públicas e práticas de linguagem no Centro-Oeste" (2013-2016).
} 
"ligado ao mundo científico", no qual se delineiam e se implementam as políticas públicas de ensino de língua(s), que "ficam a cargo de grupos da comunidade científica brasileira", e o mundo da "transmissão desses saberes", em que a Escola ocupa lugar central (SILVA, 2005, p. 4).

Para Chiss e Puech (1998, p. 12) ", "nesse campo dos saberes transmitidos", circula uma "concepção muito idealizada (não problematizada) dos saberes", pois são, frequentemente, apresentados como "disponíveis", não se perguntando sobre as formas pelas quais esses saberes são "postos à disposição".

Compreendemos esse saber institucionalizado como o que Pêcheux (2008, p. 34) denomina de "coisas-a-saber (conhecimentos a gerir e a transmitir socialmente)". É novamente Pêcheux $(2009$, p. 203) quem nos ensina que "todo efeito pedagógico se apoia sobre o 'sentido' pré-existente, sentido este produzido em formações discursivas 'semprejá-aí' e que lhe servem de matéria prima”.

Como efeito desse processo produzido pela relação Conhecimento, Estado e Sociedade (SILVA, 2007a), a disciplinarização transforma os saberes em conteúdos e produz a didatização de teorias, que, ao entrarem nos manuais ou nos instrumentos de ensino como um objeto próprio, autônomo, destituído de uma prática política e ideológica, instauram o sentido evidente de que esses saberes são fruto de um discurso consensual, na medida em que "os instrumentais vão disciplinando práticas de língua, constituindo uma memória do que seja saber a língua" (DI RENZO, 2011, p. 489) e, acrescentamos, filiados ao que se pode e deve ser "sabido"; tudo não se pode saber.

O processo de institucionalização do Programa Nacional do Livro Didático (PNLD) filia-se a uma rede complexa de determinações - que se inicia com a submissão dos livros ao edital, passando pela avaliação dos materiais, até chegar à apresentação dos títulos para a escolha dos professores - que produzem efeitos na nomeação de autores e na seleção de editoras nos editais promovidos pelo Ministério da Educação e Cultura (MEC). Chamaremos a atenção para a questão da autoria, a fim de dar visibilidade para o modo assimétrico e desigual por meio do qual se naturaliza a divisão social do trabalho da leitura em nossa sociedade; um modo de funcionamento que, por ser atravessado pelo ideológico, cristaliza e estabiliza essa divisão no processo de autoria do livro didático: a ideologia é um "mecanismo que produz e conserva as diferenças necessárias ao funcionamento das relações sociais de produção nas sociedades de classe" (HERBERT, 1967, p. 67), fazendo com que as "determinações históricas [...] apareçam como evidências empíricas" (ORLANDI, 1994, p. 57).

Esse processo de naturalização do trabalho intelectual circunscreve, de um lado, o professor da universidade, do crítico, do pesquisador, no domínio do saber, sendo-lhes concedido "o direito de produzir leituras originais, logo 'interpretações"”, e, como tal, são autorizados e legitimados a elaborar o livro didático; do outro lado, no domínio do fazer,

\footnotetext{
${ }^{4}$ Tradução nossa. No original, “dans les champs des savoirs transmis, c'est-à-dire, pour l'essentiel, dans le champ du savoir universitaire, c'est que bien des débats didactiques actuels nous semblent biaisés par une conception très idéalisée (non problématisée) des savoirs. Ceux-ci sont souvent présentés comme simplement 'disponibles' sans qu'on s'interroge vraiment sur les forms de cette 'mise à disposition'".
} 
são inscritos os sujeitos da escolarização, os professores e alunos da escola, para quem é atribuída "a tarefa subalterna de preparar e de sustentar, pelos gestos anônimos de tratamento 'literal' dos documentos, as ditas 'interpretações"”. (PÊCHEUX, 2010, p. 52). Compreendemos o funcionamento desse processo de autoria e, portanto, de autorização, como efeito das relações de força em jogo em nossa sociedade, cujos efeitos, que legitimam quem pode dizer e o que pode ser dito, ressoam no espaço escolar, um espaço tensionado, administrado e legitimado de circulação do saber, do sujeito e do sentido.

Também vemos, nesse processo de divisão social do trabalho da leitura, uma relação com a divisão do trabalho intelectual em oposição ao trabalho manual, questão que comparece no horizonte das reflexões desenvolvidas por Pêcheux, ainda sob a assinatura de Herbert (1967), na relação trabalho/não trabalho. Essa questão também produz efeitos, por meio do funcionamento da memória discursiva ${ }^{5}$, aos sentidos que trabalho admitiu em nosso passado colonial, no qual o trabalho manual estava associado ao trabalho dos escravos e o trabalho intelectual à formação das elites (SILVA, 2007b); no modo pelo qual se deu o ensino, no Brasil, a partir de uma idealização das chamadas Humanidades (associada ao campo do saber) e de uma visão restrita das Ciências (filiadas ao campo do fazer), conforme Lopes (1998); e ao trabalho nas fábricas nas sociedades capitalistas (NAVES, 1997, p. 77), no qual são opostas as tarefas de direção às tarefas de execução ${ }^{6}$.

Com o objetivo de dar visibilidade ao modo pelo qual a leitura é discursivizada nesse instrumento de ensino, apresentamos, no item a seguir, nosso gesto analítico.

\section{A ideologia da comunicação do século $\mathrm{XX}$ e seus efeitos nos instrumentos de ensino do século XXI}

Recortamos, do livro didático, a Apresentação, assinada pelas autoras do livro, para colocá-la em relação à formulação de uma atividade. Antes, porém, de apresentarmos nosso gesto interpretativo, faz-se necessário apresentar ao leitor algumas informações concernentes à forma pela qual o livro didático está organizado. Desse modo, chamamos atenção para sua estrutura. O livro é composto de:

- Uma Apresentação, assinada pelas autoras, sobre a qual nos deteremos;

- Uma apresentação sobre a organização do livro, intitulada "Conheça seu livro de Língua Portuguesa";

- Sumário;

- Introdução aos Capítulos, denominada A língua na era da informação, com subtítulos denominados Gutenberg e a invenção da imprensa e Avanços nas comunicações (grifos nossos);

\footnotetext{
5 "Saber discursivo que torna possível todo dizer e que retorna sob a forma do pré-construído, o já-dito que está na base do dizível, sustentando cada tomada da palavra" (ORLANDI, 2007, p. 31).

${ }^{6}$ De acordo com Naves, esse processo se constitui em um impedimento para "a transformação das relações de produção capitalistas". Como efeito dessa divisão, ainda nas palavras do autor, "o trabalhador direto se encontra desprovido do saber técnico e limitado a executar as ordens que lhe são assignadas, de tal sorte que o capitalista passa a exercer sobre ele um completo domínio" (ibidem, p. 76).
} 
- Quatro Unidades, compostas de dois Capítulos cada uma, totalizando oito Capítulos. Em todos os capítulos, são apresentados três textos sob o título Leitura; na sequência, atividades de Interpretação do texto e os itens Prática de oralidade, Outras linguagens, Conexões, Língua: usos e reflexão, Produção de texto e Outro texto do mesmo gênero.

- Um anexo, nomeado Projeto de leitura, com a coletânea de contos, letras de música, entrevista e obras de arte.

Acompanhemos a leitura da Apresentação:

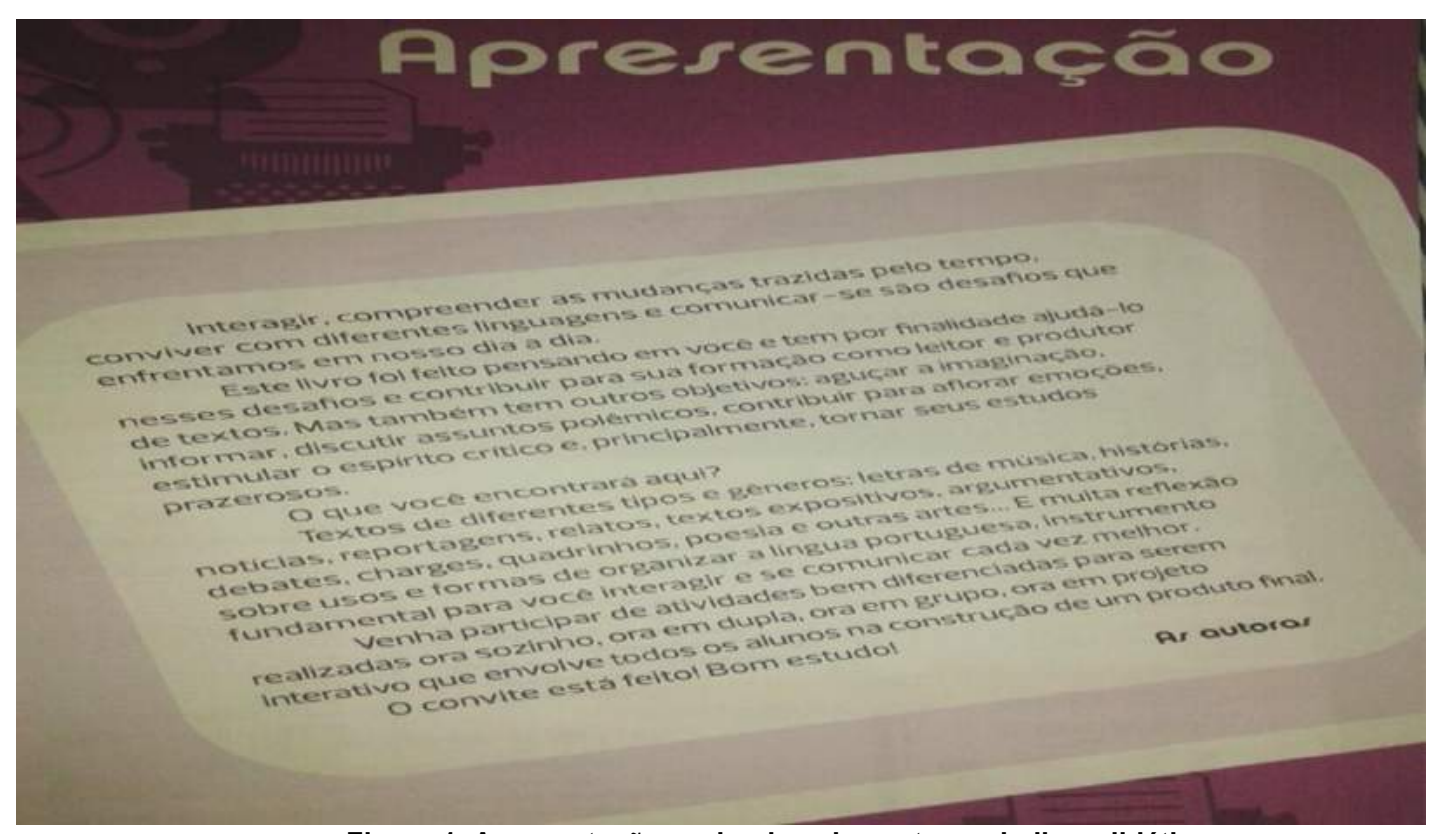

Figura 1. Apresentação assinada pelas autoras do livro didático. Fonte: Borgatto, Bertin e Marchezi (2012, p. 3).

Formulações como "Interagir, compreender as mudanças trazidas pelo tempo, conviver com diferentes linguagens e comunicar-se são desafios que enfrentamos em nosso dia a dia" são significantes que determinam a sociedade contemporânea pelos sentidos de conhecimento e de informação (DIAS, 2009) e filiam o livro à discursividade da Sociedade da Informação e do Conhecimento. A informação, da ordem do empírico, é significada, para a autora (2010, p. 60), como "um bem de mais alto valor", e o conhecimento, da ordem do material, é, para Orlandi (2010, p. 19), o "elemento estruturante de base do sistema capitalista contemporâneo".

Nessa direção, as autoras do livro didático projetam-no como um instrumento de ensino diferenciado, atualizado, inovador, "antenado" com as questões da contemporaneidade e com as necessidades de um imaginário de aluno "leitor e produtor de textos".

No entanto, vemos essa maneira de significar a língua e seu ensino no século XXI atravessada por um discurso pedagógico inscrito na ideologia da comunicação dos anos 70, legitimada na Lei de Diretrizes e Bases (LDB) de 1971, que institucionaliza o uso de 
meios de comunicação como o "rádio", a "televisão", a "correspondência" e "outros meios de comunicação" nas aulas de língua portuguesa, denominada à época de "Comunicação e Expressão"; uma memória que continuou produzindo seus efeitos mesmo após a restituição do nome da língua para "Língua Portuguesa", em 1986, momento em que se legitima o ensino do "português através de texto" (SILVA, 2005); concepções que, pelo funcionamento da ideologia, são atualizadas em nosso material: diferentes linguagens, desdobradas em diferentes tipos e gêneros, tais como letras de música, histórias, notícias, reportagens, relatos, textos expositivos, argumentativos, debates, charges, quadrinhos, poesia e outras artes ${ }^{7}$.

Lembra-nos Castellanos Pfeiffer (2001, p.41) que a escola, na tentativa de suprir "a dificuldade [...] de cumprir sua função de ensinar", propõe "a busca de textos que não sejam chatos para o aluno", entrando em jogo "a necessidade de se trabalhar com textos agradáveis". Ensina-nos a autora que "é preciso observar o quê no funcionamento discursivo da proposta de leitura pode estar produzindo o enfado da leitura. Será que são abertos espaços de interpretação para que o aluno se posicione no lugar de responsabilidade da atribuição de sentidos à linguagem?" (ibidem, p. 43-44).

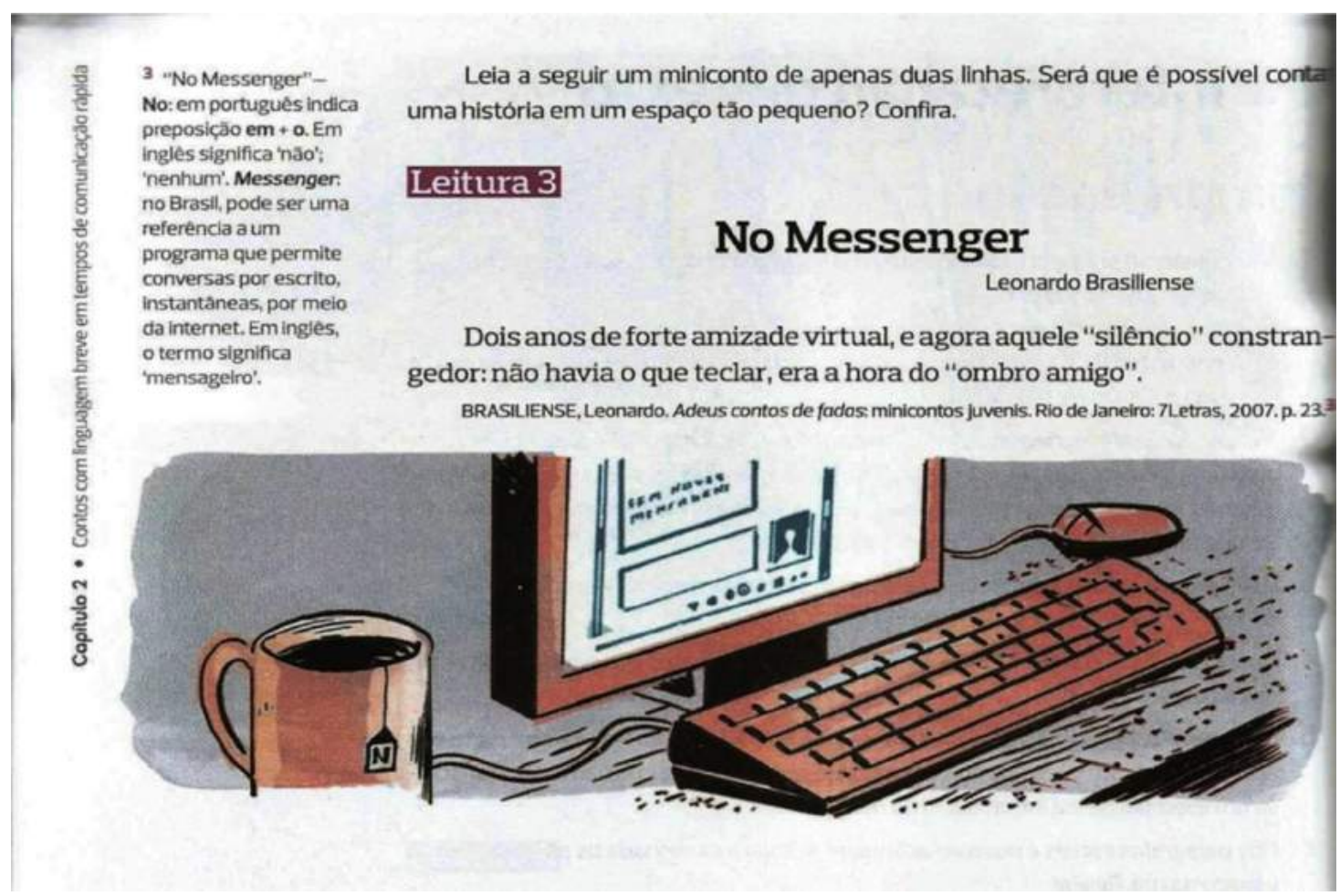

Figura 2. Apresentação do miniconto "No Messenger". Fonte: Borgatto, Bertin e Marchezi (2012, p. 54).

\footnotetext{
${ }^{7}$ Sobre a questão do gênero, sugerimos a leitura de Sériot (2008) sobre a tradução, no Ocidente, do artigo Rečevye žanry, de Bahktin, e seus efeitos para os estudos bakhtinianos; indicamos Zoppi-Fontana (2006) no que tange à relação entre a retórica e as tipologias textuais e Silva (2005) sobre a entrada dos gêneros nos Parâmetros Curriculares Nacionais (PCNs).
} 
Para analisarmos os espaços de interpretação dados aos sujeitos da escolarização no material, pousaremos nosso olhar ao miniconto No Messenger, publicado em 2007, na coletânea Adeus contos de fadas: minicontos juvenis, de autoria de Leonardo Brasiliense, publicado pela editora carioca 7 Letras, obra ganhadora de prêmios como Jabuti, Açorianos, Sul - Nacional e Livro do Ano da Associação Gaúcha de Escritores. No livro, o miniconto comparece no Capítulo 2, denominado Contos com linguagem breve em tempos de comunicação rápida, da Unidade 1, intitulado Prosa e verso na era da informação, na qual também circulam contos de Ricardo Ramos (Circuito Fechado 3), Dalton Trevisan (73) e o conto em análise.

Como proposta de atividade com a língua a partir desse miniconto, são apresentados quatro exercícios, no item denominado Interpretação, subitem Compreensão. Lembremos: na Apresentação do livro, as atividades são significadas como atividades bem diferenciadas.

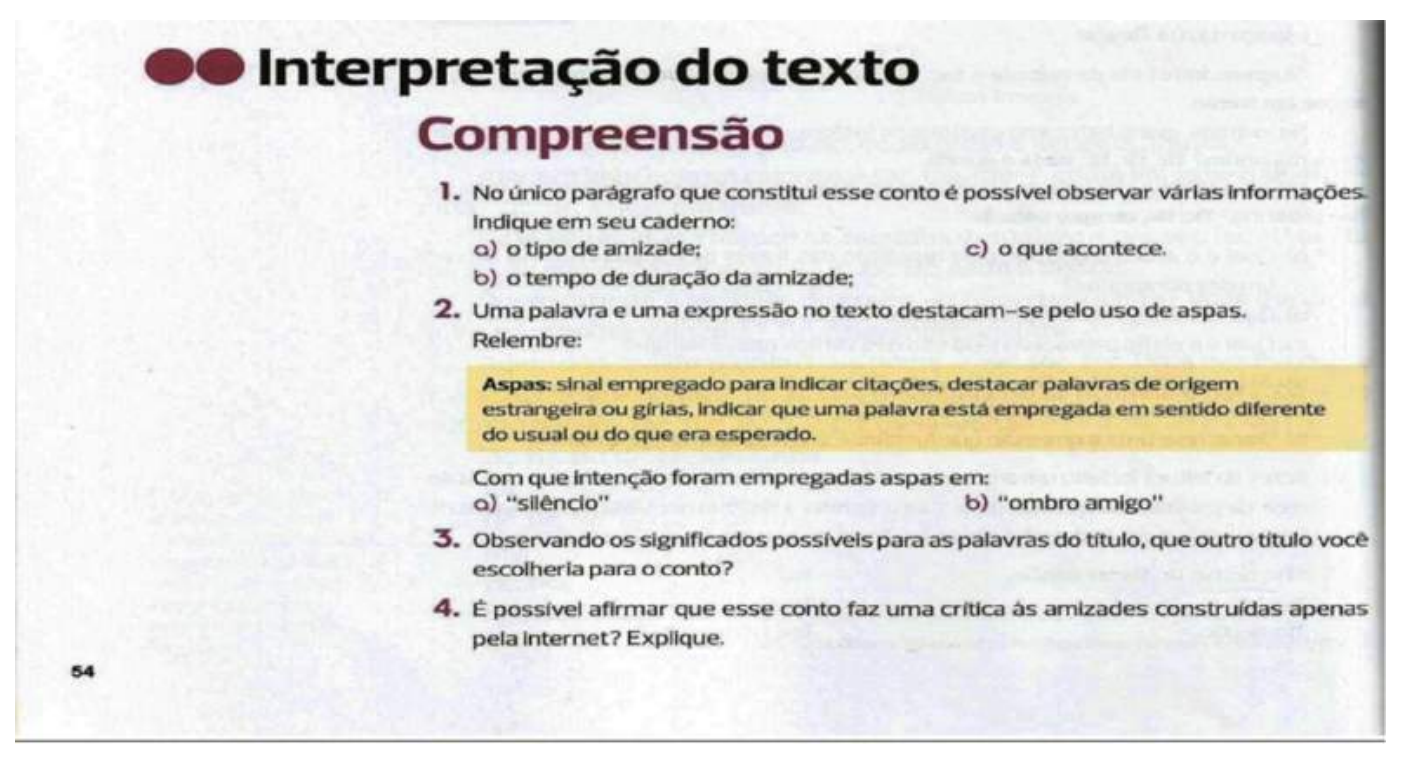

Figura 3. Apresentação das atividades de 1 a 4 sobre o miniconto "No Messenger". Fonte: Borgatto, Bertin e Marchezi (2012, p. 54).

As atividades, inscritas em uma discursividade que distingue a "Interpretação" da "Compreensão", filiam o significante "intenção" a uma regularidade nesse material, à medida que comparece ao longo das atividades no fio dos capítulos, efeito das pistas deixadas pelas autoras, na Apresentação, das relações instituídas na proposição de políticas de ensino e de língua (SILVA, 2007a), mais especificamente, no que concerne à concepção de língua em funcionamento no livro didático: instrumento fundamental para você interagir e se comunicar cada vez melhor.

Esses vestígios nos levam a circunscrever essas propostas de aprendizagem a uma concepção Pragmática de língua, concepção que produz efeitos no modo como são significados nesse material não só a língua, mas também o sujeito, o texto, a leitura, a escrita e as tecnologias. 
Nessa perspectiva, a língua é tomada "como instrumento para realizar algo, ou para manifestar intenções", por um sujeito compreendido como "uma relação entre interlocutores considerados como usuários" (GUIMARÃES, 2005, p. 124): memória que a refere ao "esquema elementar da comunicação", proposto por Jakobson, constitutivo de "emissor, receptor, código, referente e mensagem", em que a língua é significada como um canal em que se transmitem informações de forma linear, "como se a mensagem fosse resultante de um processo assim serializado” (ORLANDI, 2007a, p. 20-21).

Lembra-nos Pêcheux (2009, p. 25) que a língua se constitui numa "unidade dividida e contraditória da comunicação/não-comunicação". A crítica de Pêcheux (1984, p. 154) à Pragmática reside naquilo que se estabilizou como o "projeto empirista", no qual as "teorias comunicacionais" supõem a "interação entre emissores e receptores como espaço de produção do sentido do enunciado". Diz-nos Pêcheux e Gadet (1991, p. 105), a propósito da publicação de La langue introuvable:

Buscamos questionar a posição estratégica do mestre da língua que busca controlar um mundo de enunciados por meio de seu processo de enunciação. Contra o narcisismo da comunicação bem-sucedida, tentamos afirmar o valor político e histórico da falha.

Para refletirmos sobre a questão da interação na relação com o ensinoaprendizagem, recorremos também a Pêcheux (2008, p. 54), que nos ensina que a aprendizagem não se dá por interação, na medida em que "as coisas-a-saber" se processam "sempre tomadas em redes de memória dando lugar a filiações identificadoras e não a aprendizagens por interação: a transferência não é uma 'interação', e as filiações históricas nas quais se inscrevem os sujeitos não são 'máquinas de aprender"'. É também nessa direção que compreendemos, com Orlandi (2004, p. 130-131), que "somos seres simbólicos e históricos; nos significamos ideologicamente. Nesse sentido, a autora afirma que "é preciso que esta aprendizagem inscreva o sujeito na estrutura social, ou seja, que o constitua em suas posições de sujeito da escrita" (ORLANDI, 2002, p. 233).

Para darmos visibilidade a esses sentidos funcionando na atividade, apresentamos a análise da atividade. Dos quatro exercícios propostos pelo livro, recortamos a atividade de número 2:

2. Uma palavra e uma expressão no texto destacam-se pelo uso de aspas. Relembre:

Aspas: sinal empregado para indicar citações, destacar palavras de origem estrangeira ou gírias, para indicar que uma palavra está empregada em sentido diferente do usual ou do que era esperado.

Com que intenção foram empregadas aspas em:

a) "silêncio" b) "ombro amigo"

A maneira pela qual a atividade é textualizada, com a definição do que sejam as aspas e apontando para que servem, a regularidade no emprego de notas de rodapé nos 
capítulos, administrando e fechando sentidos, como se não pudessem ser outros, e a fragmentação da questão em itens "a" e "b", nos faz recordar o que Indursky (2006, p. 49) compreende como o texto inscrito na vertente da Linguística Textual: "uma unidade pragmático-discursiva, isto é, o autor tem certas intenções comunicativas que se fazem presentes no texto sob a forma de instruções (referências e relações) que se encontram marcadas no corpo do texto", o que também nos remete ao que a autora denomina de uma "abordagem psicolingüística da leitura, em que o texto é portador de instruções e o leitor deve decodificá-las para realizar a leitura do texto e alcançar o "sentido textual"' (ibidem, p. 49) e ao que Orlandi (2008a, p. 7) nomeia como "aprendizagem formal", na qual se processa uma "leitura imediatista" (ibidem, p.36), "como decodificação" (ibidem, p. 37), com vistas à "apreensão de um sentido" (ibidem, p. 37).

Concepção de leitura que toma o texto como um produto para rápido consumo lembremos o título do Capítulo em que o conto é apresentado: Contos com linguagem breve em tempos de comunicação rápida, reduzindo e fragmentando o texto literário, silenciando as diferentes condições em que o conto foi produzido, sua entrada no livro didático e os diferentes efeitos de sentido produzidos pelos diferentes modos de circulação (no livro de Brasiliense ou no didático da Ática), lido por diferentes sujeitos e em diferentes condições de produção. Tomamos aqui a noção de circulação de Orlandi (2008b, p.12), para quem formulação, constituição e circulação são elementos estruturantes da produção dos sentidos: "os sentidos são como se constituem, como se formulam e como circulam (em que meios e de que maneira)".

$\mathrm{Na}$ textualização dessa atividade, é interditado o gesto interpretativo de professores e alunos e, como efeito desse processo de desautorização à interpretação, em que se retira dos sujeitos o "direito à autoria" (CASTELLANOS PFEIFFER, 1995, p. 136), o que a autora chama de "produção de condições para autoria", não se dá abertura para que os sujeitos se tornem sujeitos de seus próprios gestos interpretativos. Efeito da "negação da entrada do professor e do aluno na posição de responsabilidade pelo gesto interpretativo" (ibidem, p. 79). Desse modo, podemos afirmar que não são alteradas as condições de produção da leitura nesse livro didático, uma vez que a forma pela qual a atividade é discursivizada não permite que outros sentidos, além daqueles já estabilizados e institucionalizados historicamente no livro didático, façam sentido.

É desse modo que compreendemos que as perguntas em circulação nesta atividade congelam, administram, estabilizam e silenciam sentidos, imobilizando, (con)formando e homogeneizando sujeitos, o que nos dá sustentação para afirmar que nesta atividade, sob a roupagem do diferente, repete-se o mesmo.

Quando olhamos para as possibilidades de leitura desse miniconto, vemos emergir um sujeito interpelado pela tecnologia (DIAS, 2012) que se relaciona com a escrita em sua materialidade digital, quando tecla, construindo uma escrita filiada à cultura e à memória do digitus (DIAS, 2008), numa sala de bate-papo no espaço virtual.

Essas salas, para a autora, são significadas como um espaço em que uma nova experimentação da vida se torna possível e nas quais se vê nascer um novo lugar de constituição do sujeito no ciberespaço, compreendido como um espaço discursivo, em 
sua forma material, como um espaço de significação, o que implica considerá-lo como um espaço de linguagem, um espaço político-simbólico de construção de sentido, marcado por uma temporalidade organizada a partir do acontecimento instaurado pela internet, no qual o sujeito se projeta, experimenta-se, legitima-se, torna-se visível, vai habitando, circulando e criando seus laços de pertencimento ao falar de si, do outro e com o outro (DIAS, 2012), elaborando uma escrita particular, fruto da terceira grande revolução tecnolinguística da escrita, "a do tratamento eletrônico da informação apresentada em linguagem natural” (AUROUX, 1998, p. 289).

Por meio dessa escrita, o corpo físico se inscreve na língua, produzindo a "corpografia" (DIAS, 2004, p. 140), efeito da manifestação corporal do sujeito na sala de bate-papo, textualizada na imbricada relação grafia, imagem, linguagem, afeto e tecnologia, por meio da qual se dá o acontecimento da sedução, por meio do teclar, "gesto que inscreve o corpo" (idibem, p.141), e não do olhar: um deslocamento permitido pela rede. O corpo é, portanto, lugar material no qual a significação acontece, a partir do qual as relações no espaço virtual se (re)significam.

Nesse espaço ciber, virtual, não localizável como um território do mundo físico, instituído pela tecnologia digital, se dá a ver um processo de (re)significação das relações da ordem do mundo físico ao mundo digital, no qual é possível se estabelecer uma relação de afeto, projeta-se, no miniconto, um encontro: Dois anos de amizade virtual. No entanto, o modo pelo qual a atividade foi discursivizada não abre espaço para que se tomem as salas de bate papo inscritas em sua ordem material, lugar em que uma nova experimentação da vida se torna possível, na medida em que essas questões são silenciadas na atividade.

No sentido evidente do funcionamento da rede, não se dá espaço para o silêncio, para os espaços de linguagem supostamente vazios: Agora aquele 'silêncio' constrangedor. O silêncio empírico, insuportável, produzido pela ausência da escrita, significado pelo determinante "constrangedor", também rompe com a evidência do "todos conectados" que circula na discursividade dominante do acesso ilimitado à internet, ao mesmo tempo que coloca em evidência os diferentes processos de identificação - interpelação que a rede produz em diferentes sujeitos, fazendo irromper outros sentidos...

Aqui, a inscrição do corpo do outro falta - Não havia o que teclar - e, pela falta, significa numa relação de presença - ausência, na evanescência desse sujeito, marcado pela multiplicidade. No Messenger, lemos no título em português; nenhuma mensagem na tela, No Messenger, uma possibilidade de se ler em inglês. Hora do ombro amigo. Hora de ir para uma próxima sala...

\section{Considerações finais}

Para produzirmos o efeito de fecho para este texto, compreendemos ser possível romper com o ritual pedagógico, dar voz aos sujeitos e vazão aos sentidos na sala de aula, 
à medida que o professor, por meio do processo de identificação com os sentidos, seja deslocado da posição de quem é interditado à interpretação, efeito do "veto explícito" produzido pelo livro didático (CASTELLANOS PFEIFFER, 1995, p.79), para uma posição de responsabilização pelo gesto interpretativo, em direção à abertura de um espaço para uma sua autoria, para que seus alunos também inscrevam seu dizer na repetição histórica.

Indicamos, como possibilidades de ressignificação das atividades apresentadas pelos livros didáticos ${ }^{8}$, em sentido amplo, e por esta atividade, em sentido estrito, um trabalho em sala de aula que dê condições:

a) à reelaboração dos enunciados, a fim de que deem novo sentido ao dito e visibilidade ao não-dito;

b) ao estabelecimento de relações entre os textos apresentados ao longo dos capítulos e das unidades e outros textos (que podem ser propostos pelos alunos), de materialidades significantes distintas (LAGAZZI, 2007), de diferentes modos de circulação, trabalhados na relação do impresso com o eletrônico;

c) à visibilidade das condições de produção desses textos e seus modos de significação dentro e fora do livro;

d) ao abandono da prática da consulta às respostas propostas pelo didático, tomadas como modelo, e à abertura à escuta de formulações não esperadas pelos alunos, efeito das discussões promovidas em sala de aula.

Compreendemos, assim, que esses são alguns gestos de autoria possíveis, que criam condições para o aluno se relacionar e, portanto, se significar por meio das diferentes tecnologias de escrita, à medida que transita por entre as diferentes materialidades do sentido.

É dessa perspectiva que acreditamos que os pressupostos teóricos e metodológicos da Análise do Discurso oferecem as condições para que a "leitura possa ser trabalhada [e] não ensinada" (ORLANDI, 2008a, p. 8), numa escola que, embora espaço institucional que normatiza, estabiliza e administra saberes, sujeitos e sentidos, pode produzir inovação, transformando e (re)significando as práticas de leitura e escrita na relação com a construção de um novo conhecimento.

É Pêcheux (2009, p. 281) quem nos orienta: "É preciso ousar se revoltar”!

\section{Referências bibliográficas}

AUROUX, S. A filosofia da linguagem. Trad. Bras. Campinas: Ed. da Unicamp, 1998.

\footnotetext{
${ }^{8}$ Em Vargas (2015), encontramos uma proposta de (re)significação do trabalho com a leitura com base na proposta de uma unidade deste livro didático.
} 
BORGATTO, A.T.; BERTIN, T.; MARCHEZI, V. Projeto Telaris: Português. São Paulo: Ática, 2012.

CASTELLANOS PFEIFFER, C. Escola e divulgação científica. Em: GUIMARÃES, E. (Org.). Produção e circulação do conhecimento: Estado, mídia, sociedade. Campinas: Pontes, 2001. 41-58.

Que autor é este? Dissertação. Mestrado em Linguística, Instituto de Estudos da Linguagem, Universidade Estadual de Campinas, 1995.

CHISS, J.L.; PUECH, C. De l'émergence disciplinaire à la didactisation des savoirs linguistiques: le tournant des années 60 et ses suites. Langue Française, v. 117, n. 1, 621, 1998. Disponível em http://www.persee.fr. Acesso em 23 abr. 2012.

DIAS, C.P. Sujeito, sociedade, tecnologia: a discursividade da rede (de sentidos). São Paulo: Hucitec, 2012.

Telecentros como políticas públicas de inclusão digital: da administração da vida na cidade. Em: ORLANDI, E.P. (Org.). Discurso e políticas públicas urbanas: a fabricação do consenso. Campinas: RG, 2010. 43-73.

. Imagens e metáforas do mundo. Rua [on-line], v. 2, n. 15, 15-28, 2009.

Memória \& escrita: o atravessamento de sentido das cartas no e-mail. Língua, sujeito \& história, Santa Maria, n. 37, v. 18, n. 2, 35-49, 2008.

A discursividade da rede (de sentidos): a sala de bate-papo hiv. Tese. Doutorado em Linguística, Instituto de Estudos da Linguagem, UNICAMP, Campinas, 2004.

DI RENZO, A. O Positivismo e a constituição da escola na República. Em: MALUFSOUZA, O. et al. (Orgs.). Fronteiras discursivas: espaços de significação entre a linguagem, a história e a cultura. Campinas: Pontes, 2007. 25-37.

GUIMARÃES, E. Os limites do sentido: um estudo histórico e enunciativo da linguagem. $3^{\mathrm{a}}$. ed. Campinas: Pontes, 2005.

HERBERT, T. Observações para uma teoria geral das ideologias. Rua, n. 1, 63-89, 1995.

INDURSKY, F. O texto nos estudos da linguagem: especificidades e limites. Em: ORLANDI, E.P.; LAGAZZI-RODRIGUES, S. (Orgs.). Discurso e textualidade. Campinas: Pontes, 2006. 33-80.

LAGAZZI, S. O recorte significante na memória. Em: INDURSKY, F., FERREIRA, M. C.L.; MITTMANN, S. (Orgs.). O discurso na contemporaneidade: materialidades e fronteiras. São Carlos: Claraluz, 2009. 65-78. 
LOPES, A.R.C. A disciplina química: currículo, epistemologia e história. Episteme, Porto Alegre, v. 3, n. 5, 119-142, 1998.

NAVES, M. B. Democracia e dominação de classe burguesa. Crítica Marxista, São Paulo, v. 4, 61-68, 1997.

ORLANDI, E.P. A contrapelo: incursão teórica na tecnologia - discurso eletrônico, escola, cidade. Rua [on-line], n. 16, v. 2, 5-17, 2010.

Discurso e leitura. $8^{a}$. ed. São Paulo: Cortez, 2008a.

2008 b.

Discurso e texto: formulação e circulação dos sentidos. $3^{\text {a }}$. ed. Campinas: Pontes,

Análise de discurso: princípios e procedimentos. 7ª ed. Campinas: Pontes, 2007.

Cidade dos sentidos. Campinas: Pontes, 2004.

Língua e conhecimento lingüístico. Campinas: Pontes, 2002.

. Discurso, imaginário social e conhecimento. Em Aberto, Brasília, ano 14, n. 61, 53-59, $1994 . \quad$ Disponível em http://www.rbep.inep.gov.br/index.php/emaberto/article/viewFile/911/817. Acesso em 24 maio 2012.

PÊCHEUX, M. Ler o arquivo hoje. In: ORLANDI, E.P. (Org.). Gestos de leitura. $3^{\text {a }}$. ed. Campinas: Editora da UNICAMP, 2010. p. 49-59.

Semântica e discurso. 4a ${ }^{\text {a }}$ ed. Campinas: Editora da UNICAMP, 2009.

Discurso: estrutura ou acontecimento. $5^{\mathrm{a}}$. ed. Trad. Bras. Pontes: Campinas, 2008.

(1984). Metáfora e interdiscurso. Trad. Bras. Em: ORLANDI, E.P. (Org.). Análise de Discurso: Michel Pêcheux. Campinas: Pontes, 2011. p.151-161.

PÊCHEUX, M.; GADET, F. (1991). A língua inatingível. Trad. Bras. Em: ORLANDI, E.P. (Org.). Análise de discurso: Michel Pêcheux. Campinas: Pontes, 2011. 93-105.

SÉRIOT, P. Generalizar o único: gêneros, tipos e esferas em Bakhtin. Trad. Bras. Línguas e Instrumentos Linguísticos, Campinas, Unicamp, n. 21, 75-102, 2008. Disponível em http://www.revistalinguas.com/edicao21/revista_linguas_21.pdf. Acesso em 22 mar. 2012.

SILVA, M.V. da. A escolarização da língua nacional. Em: ORLANDI, E.P. (Org.). Política lingüística no Brasil. Campinas: Pontes, 2007a. p.141-161. 
SILVA, M.V. da. História das idéias linguísticas: o Estado, as instituições, as políticas. Texto apresentado na X Jornada de História das Ideias Linguísticas, Universidade Federal de Minas Gerais, 2007b. Disponível em http://www.ucb.br/textos/2/456/ArtigosEComunicacoes/. Acesso em 06 mar. 2011.

A disciplinarização da linguística. Ciência e Estado, 2005. Disponível em http://www.ucb.br/textos/2/456/ArtigosEComunicacoes/. Acesso em 06.mar.2011.

VARGAS, O.J. Práticas de leitura na escola: uma abordagem discursiva. Dissertação. Mestrado Profissional em Letras, UNEMAT, Cáceres-MT, 2015. Disponível em http://portal.unemat.br/media/files/profLetrasCACERES/ODAIR\%20VARGAS.pdf. Acesso em: 17 nov.2015.

ZOPPI-FONTANA, M.G. Retórica e argumentação. Em: ORLANDI, E.P.; LAGAZZIRODRIGUES, S. (Orgs.). Discurso e textualidade. Campinas: Pontes, 2006. p.179-210.

Artigo recebido em: dezembro de 2016.

Aprovado e revisado em: março de 2016.

Publicado em: abril de 2017.

\section{Para citar este texto:}

SARIAN, Maristela Cury. Ensino de leitura na escola: um olhar para o livro didático. Entremeios [Revista de Estudos do Discurso, on-line], Seção Temática - Língua(gem) e Ensino, Programa de Pós-Graduação em Ciências da Linguagem (PPGCL), Universidade do Vale do Sapucaí (UNIVÁS), Pouso Alegre (MG), vol. 14, p. 261-274, jan. - jun. 2017. DOI: $\underline{\text { http://dx.doi.org/10.20337/ISSN2179-3514revistaENTREMEIOSvol14pagina261a274 }}$ 